INTERNATIONAL JOURNAL OF MULTidisciplinARY RESEARCH AND ANALYSis

ISSN(print): 2643-9840, ISSN(online): 2643-9875

Volume 04 Issue 03 March 2021

DOI: 10.47191/ijmra/v4-i3-06, Impact Factor: 6.072

Page No.- 259-261

\title{
Influence of PH on the Lethal Toxicity of Phenol, Para Chlorophenol and Pentaclorophenol to Freshwater Fish Gambusia Affinis
}

\author{
Asheera Banu Sangli \\ Department Of Zoology, M.E.S College of Arts, Commerce And Science, Malleshwaram, Bangalore
}

ABSTRACT: Phenol and Phenolic compounds has several sources including industrial wastes, coal, wood distillation, road tars, petroleum refining, chemical and plastics manufacture, domestic sewage discharges, natural sources such as plant material decay and leaching from coal and oil deposits enter natural water system and affect the fish and other aquatic organisms, So the static renewal bioassays were done to study the influence of $\mathrm{pH}$ on the lethal toxicity of phenol, para chlorophenol and pentachlorophenol to the freshwater fish Gambusia affinis. The studies shows that phenol, para chlorophenol and pentachlorophenol decreased their toxicity as the $\mathrm{pH}$ increased to the said fish.The $24,48,72$ and 96 hours $\mathrm{LC}_{50}$ values were found to be $48.0,45.0,43.0$ and $41.0 \mathrm{mg} / \mathrm{l}$ at pH 6.0 and at $\mathrm{pH} 7.5$ the 24,48,72 and 96 hours LC 50 values were 50.0, 48.0, 46.0 and $44.0 \mathrm{mg} / \mathrm{l}$ respectively for the fish exposed to phenol, And at $\mathrm{pH} 6.0$ the 24,48,72 and 96 hours LC 50 values were 24.0, 21.0, $19.0,17.0 \mathrm{mg} / \mathrm{l}$ and at $\mathrm{pH} 7.5$ the 24, 48, 72 and 96 hours were 30.0, 28.0, 25.0 and $22.0 \mathrm{mg} / \mathrm{l}$ respectively for the fish exposed to para chlorophenol.The $\mathrm{LC}_{50}$ values at $24,48,72$ and 96 hours at $\mathrm{pH} 6.0$ were $0.12,0.10,0.09$ and $0.07 \mathrm{mg} / \mathrm{l}$ respectively and at pH 7.5 The LC50 values were 1.23, 1.19, 1.15 and $1.11 \mathrm{mg} / \mathrm{l}$ respectively for the fish Gambusia affinis .

KEY WORDS: Toxicity, pH, Gambusia affinis, Phenol, Para-chlorophenol, Pentachlorophenol.

\section{INTRODUCTION}

Phenol and phenolic compounds such as para chlorophenol and pentachlorophenol have been released into natural waters from various industrial sources, phenols are used as antiseptics and disinfectants (Metelev V.V. ,et al., 1983). Phenolic compounds are non specific metabolic inhibitors, affects nervous system and also acts as hemolyzing agents of erythrocytes (Krajnovic-Ozrectic.M and et al., 1988) pentachlorophenol is used as broad spectrum pesticide, insecticide, fungicide, herbicide and it affects oxidative phosphorylation (Stephen E.D .and G.A Chapman, 1984), Environmental factor like pH influences various metabolic and physiological process of fish. Studies on the influence of $\mathrm{pH}$ on the lethal toxicity of phenol, para chlorophenol and pentachlorophenol to the fresh water fish Gambusia affinis were not done elsewhere so the bioassays were carried out..

\section{MATERIALS AND METHODS}

The live and healthy freshwater fish Gambusia affinis were acclimatized to laboratory condition for ten days in the glass aquarium and fed daily with commercial fish food and the size of the fish selected for the test were $2.8-3.6 \mathrm{cms}$ long and weighed 0.28-0.41 gms. Test medium used was one day stored tap water. The test were conducted in triplicate keeping a control. Ten fish were exposed to each concentration of phenol, para chlorophenol and pentachlorophenol separately from 40.0 to $70.0 \mathrm{mg} / \mathrm{liters}, 20$ to $40 \mathrm{mg} /$ liters , 0.01 to $2.0 \mathrm{mg} /$ liters respectively. Stock solutions were prepared by using analytical grade reagents with acetone as solvent. This required quantity of stock solution of individual type of toxicant was used to have the appropriate concentrations and the solutions were delivered to each glass aquarium to conduct the bioassay test separately. Prior to the commencement of the test feeding to the fish were stopped and were not fed during the test till the end of 96 hours. The medium used for the bioassays were dechlorinated tap water having temperature of $26.5-27.5^{\circ} \mathrm{C}$. Dissolved oxygen $6.8-7.2 \mathrm{mg} / \mathrm{liter}$ and total hardness was 78-84 mg/liter as $\mathrm{CaCO}_{3}$ (APHA et al., 1985). The test solutions were renewed every 24 hours for a period of four days. The dose mortality rate obtained for the static bioassay test were plotted on log -probit graph. The $\mathrm{LC}_{50}$ and $95 \%$ confidence limits were calculated statistically (Litchfield.J.T.. and F Wilcoxon .1949) The $\mathrm{pH}$ of medium was maintained at three different $\mathrm{pH}$ of 6.0 and 7.50 respectively during the static renewal bioassay till 96 hours for phenol, para chlorophenol and pentachlorophenol separately. 


\section{Influence of PH on the Lethal Toxicity of Phenol, Para Chlorophenol and Pentaclorophenol to Freshwater Fish Gambusia Affinis}

\section{RESULTS AND DISCUSSIONS}

Soon after the fish was introduced into various concentrations of phenol, Para chlorophenol and pentachlorophenol showed erratic and rapid movement at higher concentrations and then they slowed down their movement, surfacing and gulping of atmospheric oxygen were also seen, blood clots near the gill regions was visible, excessive mucous across gill region for the fish exposed to para chlorophenol and pentachlorophenol was seen at lower $\mathrm{pH}$, Pale coloration of the fish at the time of death was observed exposed to the higher concentrations to phenol, para chlorophenol and pentachlorophenol .

Toxicity of phenols related to $\mathrm{pH}$ were studied by Sarikoski and Vilukshela., 1982, decreased $\mathrm{pH}$ increased the toxicity of phenol the fish. The $96 \mathrm{~h} \mathrm{LC}_{50}$ values for Kharda, Singi and Patra were 9.1, 13.0, and $2.5 \mathrm{mg} / \mathrm{l}$, at pH 6.0, and at 7.3 were 32.7, 39.4, $12.5 \mathrm{mg} / \mathrm{l}$ and $\mathrm{pH} 8.8$ were $49.2,54.1$ and 29.2 respectively for the three fishes exposed to phenol (Dalela et al., 1980) . For pentachlorophenol the 24 hours $\mathrm{LC}_{50}$ was $0.028 \mathrm{ppm}$ at $\mathrm{pH} 5.5$, at $\mathrm{pH} 6.5$ was $0.044 \mathrm{ppm}$ and at pH 7.5 was $0.208 \mathrm{ppm}$ at pH 8.5 the 24 hours $\mathrm{LC}_{50}$ value was $0.40 \mathrm{ppm}$ and at $\mathrm{pH} 9.5$ was $3.126 \mathrm{ppm}$ for Cyprinus carpio respectively (Khangarot et al., 1985) The studies shows that phenol, para chlorophenol and pentachlorophenol decreased their toxicity as the $\mathrm{pH}$ increased to the Gambusia affinis .The24,48,72 and 96 hours LC 50 values were found to be $48.0,45.0,43.0$ and $41.0 \mathrm{mg} / \mathrm{l}$ at pH 6.0 and at pH 7.5 the $24,48,72$ and 96 hours $L_{50}$ values were $50.0,48.0,46.0$ and $44.0 \mathrm{mg} / \mathrm{l}$ and at $\mathrm{pH} 9.0$ the $\mathrm{LC}_{50}$ values were $60.0,58.0,56.0$ and $54.0 \mathrm{mg} / \mathrm{l}$ respectively for the fish exposed to phenol (Table 1), And at pH 6.0 the 24,48,72 and 96 hours LC 50 values were 24.0 , $21.0,19.0$ and $17.0 \mathrm{mg} / \mathrm{l}$ and at $\mathrm{pH} 7.5$ the 24, 48, 72 and 96 hours were 30.0, 28.0, 25.0 and $22.0 \mathrm{mg} / \mathrm{l}$ respectively for the fish exposed to para chlorophenol (Table 2).The LC 50 values at 24,48,72 and 96 hours at pH 6.0 were $0.12,0.10,0.09$ and $0.07 \mathrm{mg} / \mathrm{l}$ and at $\mathrm{pH} 7.5$ the were 1.23, 1.19, 1.15 and $1.11 \mathrm{mg} / \mathrm{l}$ for the fish Gambusia affinis exposed to pentachlorophenol respectively (Table 3).

\section{REFERENCES}

1) $\mathrm{APHA}$ (American public health association) American water works association and water pollution control federation 1985 Standard methods for the examination of water and waste water, $16^{\text {th }}$ edition, Am..Publ .HIth..Assoc., New York, USA

2) Dalela .R.C., Rani .S and Verma .S.R 1980. Influence of $\mathrm{pH}$ on the toxicity of phenol and its two derivatives pentachlorophenol and dinitrophenol to freshwater teleosts .Acta. Hydrochem.. Hydrobiol. 8: 623-629

3) Khangorot B.S Sehgal A, B., Jain M.L., 1985. Effect of pH on the toxicity of NaPCP to fry of common carp in soft water, Arch Hydrobiol . 103 (3) : 375-379

4) Krajnovic-Ozretic,M and Ozretic.B 1988 Toxic effect of phenol on grey mullet. Mugil ouratus. Resso.. Bull. .Environ. Contam. Toxicol 40: 23-29

5) Litchfield .J.T and Wilcoxon F. 1949. A simplified method of evaluating dose effect experiments. J..Pharmocol.Exp..Ther. 96: 43-99.

6) Metelev.V.V., Kanaev A.I., Dzasokhava.N.G. 1983 Water toxicology Amerind Publishing Pvt Ltd. New Delhi.

7) Saarikoski. J and Vilukshela M 1982 Relation between physico Chemical properties of phenols and their toxicity and accumulation in fish..Ecotoxicol..Environ..Safety 6:501-502

8) Stephen. E.D and G. A. Chapman 1984. Effect of pentachlorophenol on the growth and mortality of embryonic and juvenile steelhead trout.Arch.Environ.Contam.Toxicol..13:739-743

Table 1: $L C_{50}$ Values and 95 percent confidence limit for the fish Gambusia affinis exposed to Phenol.at two different $\mathrm{pH}$

\begin{tabular}{|l|l|l|l|l|}
\hline $\mathrm{pH}$ & 24 hours & 48 hours & 72 hours & 96 hours \\
\hline 6.0 & $48.0(47.19-48.81)$ & $45.0(44.29-45.72)$ & $43.0(42.49-43.51)$ & $41.0(40.67-41.32)$ \\
\hline 7.5 & $50.0(47.80-52.30)$ & $48.0(47.01-49.00)$ & $46.0(44.48-47.56)$ & $44.0(42.88-45.14)$ \\
\hline
\end{tabular}

Table 2: $L C{ }_{50}$ Values and 95 percent confidence limit for the fish Gambusia affinis exposed to Para chlorophenol.at two different $\mathrm{pH}$

\begin{tabular}{|l|l|l|l|l|}
\hline $\mathrm{pH}$ & 24 hours & 48 hours & 72 hours & 96 hours \\
\hline 6.0 & $24.0(22.51-25.58)$ & $21.0(19.84-22.21)$ & $19.0(18.11-19.93)$ & $17.0(16.44-17.57)$ \\
\hline 7.5 & $30.0(28.35-31.74)$ & $28.0(26.76-29.28)$ & $25.0(24.10-25.92)$ & $22.0(21.27-27.37)$ \\
\hline
\end{tabular}


Influence of PH on the Lethal Toxicity of Phenol, Para Chlorophenol and Pentaclorophenol to Freshwater Fish Gambusia Affinis

Table 3: $L C 50$ Values and 95 percent confidence limit for the fish Gambusia affinis exposed to Pentachlorophenol at two different $\mathrm{pH}$

\begin{tabular}{|l|l|l|l|l|}
\hline $\mathrm{pH}$ & 24 hours & 48 hours & 72 hours & 96 hours \\
\hline 6.0 & 0.12 & 0.10 & 0.09 & 0.07 \\
& $(0.10-0.13)$ & $(0.09-0.10)$ & $(0.08-0.09)$ & $(0.06-0.07)$ \\
\hline 7.5 & 1.23 & 1.19 & 1.15 & 1.11 \\
& $(1.20-1.25)$ & $(1.16-1.21)$ & $(1.12-1.17)$ & $(1.09-1.12)$ \\
\hline
\end{tabular}

